of the earth. Actually, however, if the water is allowed to come to complete rest in a vessel where the hole is accurately in the middle, and if the plug is carefully withdrawn, no whirlpool is formed. The whirlpool that is generally observed is due to some slight rotation given to the water near the edge of the vessel, which, by the laws of fluid motion, becomes very much accentuated where the water runs out. The direction of the spin depends on the direction of this slight motion. If the spin is actually always in the same direction in a particular bath, it is because of some chance influence, such as the position of the taps. The spin of the earth should actually give rise to a rotation of the water where it runs out, but the effect is far too small to be observed with a bath or basin. Where a large still sheet of water runs out through a vertical pipe, as at the intake of a water turbine, the effect should, however, be large enough to observe. It is, in fact, found that under these conditions whirlpools form, and that the spin of the water is in an opposite direction in the northern and in the southern hemisphere, as it should be. The consideration of vortices is extremely important for aircraft or other bodies moving through the air, and the whole object of stream-lining is to avoid the formation of vortices, which fritter away energy. The sensitive flame, which ducks in response to sounds, is, it turns out, an example of vortex motion, the vortices being produced as a consequence of the sound vibration.

\section{New Guinea Exhibition}

AN exhibition of ethnographical objects from New Guinea and the islands of the Malay Archipelago under the auspices of the Royal Anthropological Institute opened at 10 Grosvenor Square, London, S.W., on May 26, and will remain open for three or four weeks. The specimens were collected by Lord Moyne during a cruise on his yacht Rosaura between November and February last, and with them is a remarkable series of photographs taken at the same time by Lady Broughton. The section of the exhibition which will afford the greatest interest is that illustrating the culture of the newly discovered Aiome, a light-skinned pygmy race inhabiting the hills near the Middle Ramu River in the mandated territory of New Guinea, who had not previously had any contact with white civilisation. Their skin is only slightly darker than that of a well-sunburned European, and their hair a very dark brown. The average height is $4 \mathrm{ft} .6 \frac{1}{2}$ in., male, and $4 \mathrm{ft}$. 2 in., female. They are surrounded by dark-skinned tribes of normal stature and the general New Guinea type. Their appearance is well illustrated in a number of photographs, which show the mode of wearing the articles of adornment included in the collection, such as bands made up of stems of Dendrobium and threaded grass seeds, and tree-bark head-dresses. A collection of skulls comes from a deserted village, in which they were stored in bundles outside or inside the houses. This collection includes two very distinct types of head, one large and one small. The former is distinctly Australoid in appearance, with prominent brow ridges and receding forehead. It is remarkable as coming from New Guinea. No explanation of the abandonment of the village was obtained, though it was found to be full of the possessions of its former inhabitants, including a number of objects of the greatest cultural interest, among them drums, carved shields and curious head-dresses of possibly ritual purpose.

\section{Homer's Troy}

A THIRD, and possibly final, stage in the archæological exploration of Troy has been reached with the excavations organised by the University of Cincinnati under the field direction of Dr. Carl Bleger, formerly assistant director of the American School of Archæology at Athens. It is remarkable that of the three great sites of Homeric civilisation, Troy, Mycenæ and Tiryns, the first-named, which inspired the excavation of the archæological sites of the eastern Mediterranean, should still, at the last, afford a problem in the exact determination of its chronological and cultural relations. Schliemann's final identification of the Sixth City at Hissarlik, and not the Second, as the Homeric Troy in 1890, and Dorpfeld's demonstration of a sequence of nine phases in the history of the city, extending from the Early Bronze Age to Roman times four years later, satisfied a generation which knew not Knossos and the history of Helladic culture. It has since become evident that the Sixth City, notwithstanding $\mathbf{M y}$ cenæan contacts, is neither completely contemporary with, nor its culture identical with that of, the Mycenæan age. The work of the American expedition, as is indicated by Mr. E. J. Forsdyke in his lucid summary of the present position of the archæological and historical problem in The Times of May 22, has confirmed this by showing that the Sixth City goes back to Pre-Mycenæan Middle Helladic, and that "the Achæan moment", the period when the Achæan military aristocracy held sway, fortified by matrimonial alliances with Mycenæan heiresses, which corresponds with the conditions of the Homeric world, is represented by an inferior reconstruction after the Sixth City had been destroyed by earthquake about 1300 B.c., in which the walls were repaired in rougher masonry and the houses irregularly built with odd stones from the ruins. About 1200 B.c. this Seventh City was destroyed by fire. It was rebuilt and inhabited, presumably, by the Achæan conquerors.

\section{Co-ordination of Research}

The Research Co-ordination Committee, which was formed a few months ago as the result of an informal meeting of persons connected with organisations interested in the application of science to present-day problems (see NATURE, February 22, p. 311), reported on its activities at a meeting on May 23 to the group from which it arose. The Committee, after making a preliminary list of problems which need co-ordination, decided to consider one or two in detail and to work out a technique of co-ordination that could be generally 
employed. This, it is claimed, has been achieved. Given two persons sufficiently interested in coordinating the material relating to an important problem, and ready to devote to it one full evening a week, the Committee will undertake to help them in elucidating the various aspects of the problem and in bringing together the organisations concerned. The Research Co-ordination Committee has been fortunate in obtaining the co-operation of many organisations interested in various aspects of the housing question. Among these are the Housing Centre, Architectural Association, Modern Architectural Research Association, Architects and Technicians Organisation, Society of Women Estate Managers, Kitchen Planning Centre, Women's Gas Council, Institute of Sociology, etc. The Building Research Station of the Department of Scientific and Industrial Research and the Housing Section of the Ministry of Health have also provided assistance.

\section{Lighting and Heating Research}

A Conference on lighting, space heating and hot water supply in low-cost housing, arranged by the Housing Centre, 13 Suffolk Street, S.W.1, was held on May 25 and 26. In the opening address, Lord Elton referred to cheapness, efficiency and health requirements as the main directives in modern lowcost house building and contrasted them with the durability, dignity and individuality of the Tudor period. In the discussion that followed, Prof. Patrick Abercrombie, who was in the chair, pointed out that standardisation can be applied to desirable as well as undesirable features, and other contributors suggested that perhaps dignity and individuality can now be transferred from the individual house to a planned estate as a whole. Sir Richard Paget, in his address as chairman of the business part of the Conference, gave a broad view of some of the avenues opened by scientific research in the utilisation of our national fuel assets, and pointed out several cases of present wastage. He directed attention to Sir Richard Gregory's remarks at the Royal Institution on the mission of science in the changing world of to-day. $\mathrm{He}$ also stressed the urgent need of an impartial investigation of the monetary system, and ended by pointing out the value of technical conferences in bringing together experts and enabling them to synthesise their ideas into one connected whole.

THE relative merits of gas, electricity and other forms of heating were brought out in a series of papers contributed by the British Commercial Gas Association, British Electrical Development Association, Coal Utilization Council, London and Counties Coke Association and by other organisations and individual specialists. The convergence upon a common problem of these diverse interests has been a valuable feature of the Conference. The need for an impartial body to collect and collate the data supplied by the various parties was brought out, and both the Housing Centre and the Research Coordination Committee have expressed their willingness to help in this work. The immediate task of such a body would be, first, to find out what the consumer actually uses and is likely to expect with an increased standard of living and, secondly, how far his requirements can be satisfied with existing methods and appliances, or such improved forms as the advance in technique renders possible.

\section{Radium Research at Birmingham}

For some time the Physics Department of the University of Birmingham has had charge of $0.5 \mathrm{gm}$. of radium, which has been used for supplying local hospitals with radon. This radium, which belonged to the Radium Commission, has recently been allotted to the General Hospital of the City for a special purpose. It therefore appeared likely that the Radon Laboratory of the Department of Physies at the University would be put out of action. Thereupon Sir Gilbert Barling issued an appeal for a fund to provide the University with a supply of radium of its own. The appeal met with a most generous response, and with the accruing money it is proposed to buy for the University $1 \mathrm{gm}$. of radium, so that the Radon Laboratory will be able to continue to supply radon to hospitals as before, and the Physics Department will have radium available for scientific research. The Pro-Chancellor (Mr. Walter Barrow) has expressed on behalf of the University his warmest thanks to Sir Gilbert Barling for his energy and initiative and to the donors for their generous response.

\section{Conference on Atmospheric Pollution}

THE half-yearly Conference of representatives of local authorities and other organisations co-operating with the Department of Scientific and Industrial Research in the investigation of atmospheric pollution was held in the offices of the Department on May 25. The Conference received from Dr. G. M. B. Dobson, chairman of the Atmospheric Pollution Research Committee, a report on the progress of research. $\mathrm{He}$ announced that the Committee has decided to undertake an intensive survey of the pollution in and around an industrial centre and has selected the city of Leicester, the geographical position of which in relation to the surrounding country and neighbouring centres of population appears to render it particularly suitable. The Conference noted with interest that the London County Council has intimated that it is extending its investigations and that it is arranging for observations at a rural institution and a seaside institution belonging to it. Reports from Glasgow and from Sheffield and Rotherham were presented on comparative determinations of sulphur in filtered and unfiltered air. Measures for reducing pollution due to the emission of ash and grit from chimneys were also discussed. At its previous meeting, the Conference considered a proposal by the London County Council that the machinery of the Conference might be used to secure financial contributions for investigations into means for reducing this type of pollution. A committee, which was appointed to meet representatives of the Department for the discussion of practical measures, presented a report for discussion by the Conference. 